Andriy SVERSTIUK ${ }^{1}$, Oksana BAHRII-ZAIATS ${ }^{2}$, Aleksandra KLOS-WITKOWSKA ${ }^{3}$, Ihor ANDRUSHCHAK ${ }^{4}$

Scientific supervisor: Vasyl MARTSENYUK ${ }^{5}$

DOI: https://doi.org/10.53052/9788366249868.25

\title{
PODEJŚCIE DO ROZWOJU CYBERFIZYCZNYCH SYSTEMÓW PROCESÓW MEDYCZNYCH I BIOLOGICZNYCH
}

\begin{abstract}
Streszczenie: Praca koncentruje się na opracowaniu systemu Big Data pozwalającego na inteligentne przetwarzanie danych medycznych, które są pozyskiwane z różnych źródeł i różnego typu. Artykuł oferuje opis matematyczny dynamiki dyskretnej populacji w połączeniu z dynamiczną logiką badanych modeli najbardziej zaawansowanych biosensorów, takich jak macierze biopikseli, które są wykorzystywane na etapie analitycznym naukowego uczenia maszynowego. Uzyskuje się wyniki symulacji komputerowej modeli matematycznych CPS procesów medycznych i biologicznych w postaci obrazów antygenów, przeciwciał, połączeń antygenów z przeciwciałami, pikseli fluorescencyjnych.
\end{abstract}

Słowa kluczowe: system cyberfizyczny (CPS), Big Data, stabilność modelu, równania różniczkowe, równania różnicowe, siatka prostokątna, siatka heksagonalna

\section{APPROACH TO THE DEVELOPMENT OF A CYBER-PHYSICAL SYSTEMS OF MEDICAL AND BIOLOGICAL PROCESSES}

Summary: The work focuses on developing a Big Data system allowing us to process medical data intelligently, which are ingested from different sources and of various types. The paper offers the mathematical description of the discrete population dynamics in combination with the dynamic logic of the studied models of the most advanced biosensors as biopixels arrays which are used at the analytics stage of scientific machine learning. The results of computer simulation of mathematical models of CPS of medical and biological processes in the form of images of antigens, antibodies, connections of antigens with antibodies, fluorescent pixels, and an electrical signal from the converter are obtained.

Keywords: cyber-physical system (CPS), Big Data, stability of the model, differential equations, difference equations, rectangular lattice, hexagonal lattice

${ }^{1}$ I. Horbachevsky Ternopil National Medical University, sverstyuk@tdmu.edu.ua

${ }^{2}$ I. Horbachevsky Ternopil National Medical University, bagrijzayats@tdmu.edu.ua

${ }^{3}$ University of Bielsko-Biala, awitkowska@ath.bielsko.pl

${ }^{4}$ Lutsk National Technical University, 9000@Intu.edu.ua

5 Professor, Dr hab., University of Bielsko-Biala, Department of Computer Science and Automation,vmartsenyuk@ath.bielsko.pl 


\section{Introduction}

Over the last decade, we have seen a rapid growth of digital developments, including a variety of sensors, microcontrollers, communication systems to meet societal needs. Biosensors play a critical role in the Internet of Things when it comes to eHealth. There are a number of sensors available on the market that help people monitor their daily fitness, blood glucose levels, and many sensible applications of primary diagnostics at home. In [1] the problems of safe and confidential use of the most modern biosensors for the Internet of Medical Things are considered.

The architecture of intelligent monitoring of electronic health of patients with chronic diseases is presented in [2]. Elements of the architecture include portable devices, biosensors, and smartphones for collecting medical and biological indicators [3]. The intelligent system uses scientific machine learning (SciML) as a tool for analytics in the context of complex applications across science, engineering, and medicine [4]. It focuses on Big Data, obtained from various hospitals, and data obtained from the patient, to diagnose and generate warnings of critical and crisis situations. The system of health monitoring using prognostic calculations using Big Data analysis is presented in [5]. Google works with US clinics to track searches for the COVID-19 pandemic and to predict in which region the outbreak will occur [6].

At present, the integration between computing and physical resources leads to the creation of complex computing systems with distributed parameters [7]. In recent years, we have seen an interest in cyber-physical systems (CPS), which are tools for controlling and monitoring the studied indicators using computer technology, in which software is closely related to physical objects. CPS of medical and biological processes are used to measure and analyze biochemical parameters in biological fluids, detection of cancer, markers of heart failure, pathogenic bacteria, to determine the level of contamination of food and the environment. In recent years, CPSs have been used effectively, in which the function of selective elements is performed by biosensors. Such systems are called cyber-physical biosensor systems (CPBSS), which have a number of advantages: high selectivity, stability, performance, affordable cost, the ability to use a wide range of users.

As a result of the use of CPBSS, Big Data is obtained, which requires processing and interrelation with the measured medical and biological parameters. For Big Data analysis, SciML is used as a data-driven method for studying computer algorithms that are automatically improved through experience [8].

In CPS, "experience" is usually presented in the form of data, and SciML allows you to create mathematical models based on sample data for forecasting and decision making. SciML has made significant strides in a variety of fields, including computer vision, language recognition, and control systems, as well as related scientific fields in physics, chemistry, and biology [9].

Algorithms and methods for processing measurement parameters in the CPS of medical and biological processes using Big Data are created on the basis of their mathematical models. Mathematical models of biosensors for CPBSS on rectangular lattice using lattice differential equations with delay have been developed $[10,11]$. 


\section{Mathematical model of biosensor of the intelligent Big Data system of medical and biological processes on hexagonal lattice using lattice difference equations with delay}

For the intelligent Big Data system of medical and biological processes dynamics, we use the mathematical description with the help of nonlinear difference equations with delay.

The model of the biosensor on the basis of a hexagonal lattice is considered. In this case, for the numbering of biopixels $(i, j, k), i, j, k=\overline{-N, N}, i+j+k=0$ the cubic coordinate system is used.

Let $V_{i, j, k}(t)$ is the concentration of antigens, $F_{i, j, k}(t)$ is the concentration of antibodies in the biopixel $(i, j, k), i, j, k=\overline{-N, N}, i+j+k=0$.

The model is based on such biological assumptions for an arbitrary biopixel $(i, j, k)$. 1. Antigens are detected, bind, and finally neutralized by antibodies with some probability velocity $\Upsilon>0$.

2. It is assumed that when colonies of antibodies are absent, colonies of antigens are regulated by a logistic equation with a delay:

$$
V_{i, j, k}(n+1)=\left(1+\beta-\delta_{v} V_{i, j, k}(n-r)\right) V_{i, j, k}(n),
$$

where $\beta$ and $\delta_{v}$ - positive numbers, and $r>0$ mean latency of the negative responce of the antigens' colonies.

3. The fertility rate $\beta>0$ for the antigen population is introduced.

4. Antigens are neutralized by antibodies at a certain probability rate $\Upsilon>0$.

5 . The population of antigens tries to reach a certain limit of saturation with a speed $\delta_{v}>0$.

6. The diffusion of antigens from six adjacent pixels is considered $(i+1, j, k-1)$, $(i+1, j-1, k),(i, j-1, k+1),(i-1, j, k+1),(i-1, j+1, k)$ and $(i, j+1, k-$ 1) (Figure 1) with diffusion speed $D \Delta^{-2}$, where $D>0$ - coefficient of diffusion; $\Delta>$ $0-$ distance between two adjacent pixels.

7. The constant mortality of antibodies $\delta_{v}>0$ is introduced.

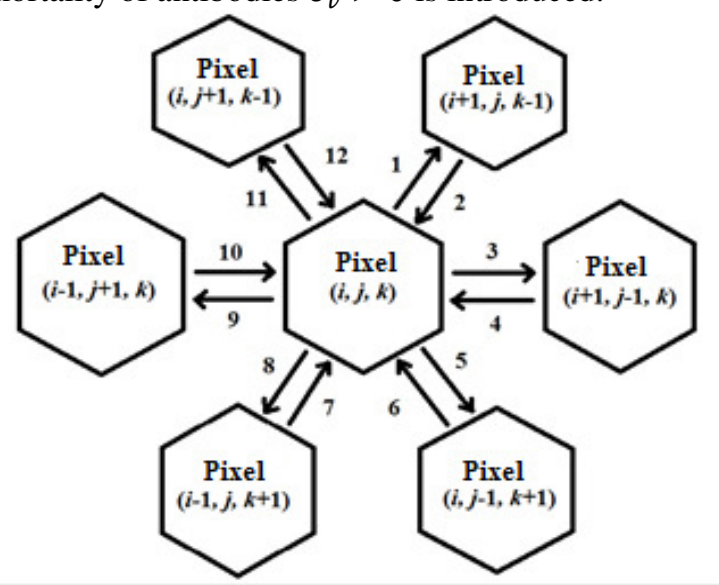

Figure 1. Hexagonal lattice, which binds six neighboring pixels in the model of the biopixels using the cubic coordinates: $1,3,5,8,9,11-\left(\frac{D}{\Delta^{-2}} V_{i, j, k}(t)\right)$; 


$$
\begin{aligned}
& 2-\left(\frac{D}{\Delta^{-2}} V_{i+1, j, k-1}(t)\right) ; 4-\left(\frac{D}{\Delta^{-2}} V_{i+1, j-1, k}(t)\right) ; 6-\left(\frac{D}{\Delta^{-2}} V_{i, j-1, k+1}(t)\right) ; \\
& 7-\left(\frac{D}{\Delta^{-2}} V_{i-1, j, k+1}(t)\right) ; 10-\left(\frac{D}{\Delta^{-2}} V_{i-1, j+1, k}(t)\right) ; 12\left(\frac{D}{\Delta^{-2}} V_{i, j+1, k-1}(t)\right) .
\end{aligned}
$$

8. As a result of the immune response the antibody density increases with a probabilistic velocity $\eta \Upsilon$.

9. The antibody population is approaching a certain level of saturation with a speed $\delta_{f}>0$.

10. The immune response occurs with some constant delay in a time $r>0$.

On the basis of the above information, we will write the mathematical model of lateantigen-antibody interaction for a hexagonal array of biopixels using based on the well-known Marchuk model [12] and uses the spatial operator $\hat{S}$ proposed in [13].

$$
\begin{aligned}
& V_{i, j, k}(n+1)=V_{i, j, k}(n) \exp \left\{\beta-\Upsilon F_{i, j, k}(n-r)-\delta_{v} V_{i, j, k}(n-r)\right\}+\hat{S}\left\{V_{i, j, k}(n)\right\}, \\
& F_{i, j, k}(n+1)=F_{i, j, k}(n) \exp \left\{-\mu_{f}+\eta \Upsilon V_{i, j, k}(n-r)-\delta_{f} F_{i, j, k}(n)\right\}, n>0 . \\
& \text { where } \hat{S}\left\{V_{i, j, k}\right\} \text { is a discrete diffusion for a spatial operator } \hat{S} \text {. } \\
& \qquad V_{i, j, k}(n)=V_{i, j, k}^{0}(n) \geq 0, \quad F_{i, j, k}(n)=F_{i, j, k}^{0}(n) \geq 0 \\
& n \in[-r, 0), \quad V_{i, j, k}(0), F_{i, j, k}(0)>0 .
\end{aligned}
$$

\section{Dynamic logical simulation of intelligent Big Data system for investigation the stability of CPS of medical and biological processes.}

In order to simulate the dynamic logic of an intelligent Big Data system for investigation the stability of CPS of medical and biological processes, we use the syntax proposed by A. Platzer for the general CPS [14]. The CPS uses the Hybrid Programming Language (HP), which has more features than differential equations. Consider the dynamic logical simulation of intelligent Big Data system for investigation the stability of CPS of medical and biological processes on the example of a mathematical model of biosensor on hexagonal lattice using lattice difference equations with delay. The first level of HP is a dynamic program that is defined by the following grammar

$a::=V_{i, j, k}(n+1)=V_{i, j, k}(n) \exp \left\{\beta-\Upsilon F_{i, j, k}(n-r)-\delta_{v} V_{i, j, k}(n-r)\right\}+$ $\hat{S}\left\{V_{i, j, k}(n)\right\}$,

$F_{i, j, k}(n+1)=F_{i, j, k}(n) \exp \left\{-\mu_{f}+\eta \Upsilon V_{i, j, k}(n-r)-\delta_{f} F_{i, j, k}(n)\right\} \& \Phi_{t}$.

where $\Phi_{t}$ is an evolutionary domain constraint in the form of a formula for the logic of the first order of real arithmetic

$$
\begin{gathered}
\Phi_{t} \stackrel{\text { def }}{=} V^{\text {min }} \leq V_{i, j, k}(n) \leq V^{\max } \\
\wedge F^{\text {min }} \leq F_{i, j, k}(n) \leq F^{\text {max }} \wedge i, j, k=\overline{-N, N} \wedge n>0, i+j+k=0
\end{gathered}
$$

The functioning of the biopixel $(i+j+k)$ is determined by two states, with respect to fluorescence. Namely, $s_{f l}$ is a state of fluorescence and $s_{n o n} f l$ is one of the nonfluorescence states. The use of the first order of semantics of logic and the satisfaction ratio $s \mid=L$ for the first-order formula $L$ of real arithmetic and state $s$ can be determined for some pixels $(i, j, k) ; i, j, k=\overline{-N, N}, i+j+k=0$ states $s_{f l}$ and $s_{\text {non } f l}$ as 


$$
\begin{gathered}
s_{f l} \mid=k_{f l} V_{i, j, k}(n) F_{i, j, k}(n) \geq \theta_{f l}, \\
s_{n o n f l} \mid=k_{f l} V_{i, j, k}(n) F_{i, j, k}(n)<\theta_{f l} .
\end{gathered}
$$

Discrete changes occur in computer programs when they accept new values for variables. This situation occurs when a fluorescence phenomenon occurs in a pixel $(i, j, k) ; i, j, k=\overline{-N, N}, i+j+k=0$. The state $s_{f l, i, j, k}:=1$ is assigned a value of 1 to the variable $s_{f l, i, j, k}$. This leads to a discrete, jump-like change, as the value $s_{f l, i, j, k}$ does not change smoothly, but rapidly when it suddenly changes from 1 to $s_{f l, i, j, k}$, causing a discrete jump of values $s_{f l, i, j, k}$. In this way, we obtain a discrete model of change $s_{f l, i, j, k}:=1$, except for the model of change (6).

\section{Software complex of the intelligent Big Data system for investigation the stability of CPS of medical and biological processes}

The software package for the intelligent Big Data system for investigation the stability of CPS of medical and biological processes consists of the following main software modules: unit of ingesting and processing Big Data used to identify input parameters of the model of CPS, the software module of research of dynamic behavior of CPS, the software module of research of dynamic logic of CPS, the block of decisionmaking on stability of CPS, the block of visualization, lattice images of antigen/antibody data source, a data source that receives lattice images of antigen binding to antibodies and a database that receives images of fluorescent biopixels.

A software package for the study of CPS phase diagrams using the $\mathrm{R}$ package (http://www.r-project.org/) has been developed [15]. The block diagram of the software package of the intelligent Big Data system for investigation the stability of CPS of medical and biological processes is shown in Figure 2.

The software module for studying the dynamic behavior of CPS consists of blocks for obtaining bifurcation and phase diagrams. Using software to study the stability of intelligent Big Data system for investigation the stability of CPS of medical and biological processes, obtained the results of computer simulation in the form of bifurcation and phase diagrams of antigen populations relative to antibodies, lattice images of antigens, antibodies, probabilities of antigen binding to antibodies and antibodies, the signal from the converter. The software module for studying the dynamic logic of CPS consists of blocks for modeling lattice images of antigens/antibodies, block for obtaining lattice images of antigen binding to antibodies, obtaining images of fluorescent biopixels and the electrical signal from the converter. 


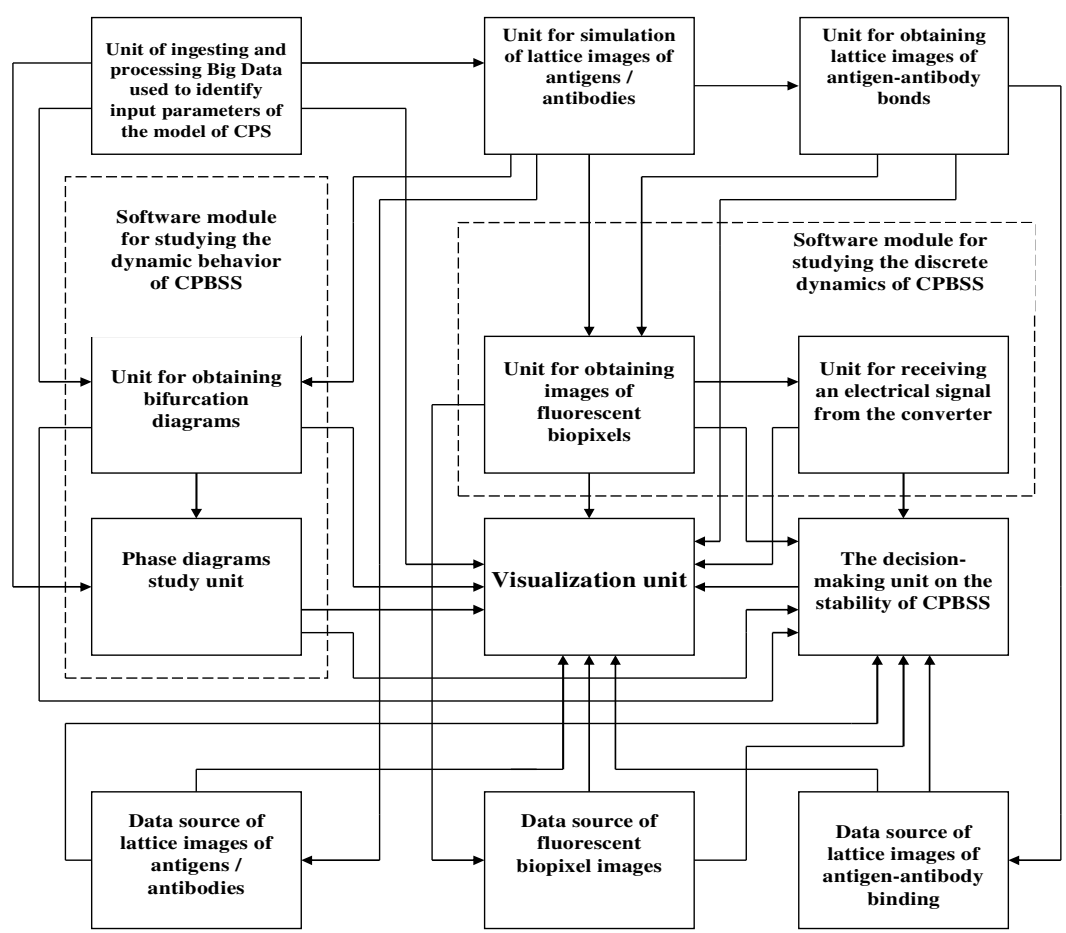

Figure 2: Block diagram of the software package of the intelligent Big Data system for investigation the stability of CPS of medical and biological processes

The study of CPS stability of medical and biological processes based on the Big Data intelligent system is an important data source: lattice images of antigen/antibody data source, a data source that receives lattice images of antigen binding to antibodies, and a database that receives images of fluorescent biopixels.

\section{Computer simulation of mathematical models of biosensors using an intelligent Big Data system for investigation the stability of CPS of medical and biological processes}

4.1. Parameters of mathematical models of biosensors for investigation the stability of CPS of medical and biological processes

A software package for the study of CPS phase diagrams using the $\mathrm{R}$ package (http://www.r-project.org/) has been developed [15]. To study the occurrence of bifurcation and deterministic chaos in compartmental mathematical models of lattice type on a rectangular lattice using differential equations, models (1), (4) at $N=4$ and values of $\beta=2 \mathrm{~min}^{1}, \Upsilon=2 \frac{\mathrm{ml}}{\mathrm{min} \cdot \mathrm{mkg}}, \mu_{f}=1 \mathrm{~min}^{1}, \eta=\frac{0.8}{\Upsilon}, \delta_{v}=0.5 \frac{\mathrm{ml}}{\mathrm{min} \cdot \mathrm{mkg}}, \delta_{f}=$ $0.5 \frac{\mathrm{ml}}{\mathrm{min} \cdot \mathrm{mkg}}, D=0.2 \frac{\mathrm{nm}^{2}}{\mathrm{~min}}, \Delta=0.3 \mathrm{~nm}$ are considered. The concentrations of antigens 
populations $V_{i, j}(t), V_{i, j, k}(t)$ and antibodies populations $F_{i, j}(t), F_{i, j, k}(t)$ are measured in $\frac{m k g}{m l}$.

\subsection{Results of computer simulation of mathematical model of biosensor on hexagonal lattice using lattice difference equations with delay}

The long - term behavior of model (4) at $r=5, r=17, r=22$ with a set of parameter values, which are presented above (Fig. 3 - 6), is analyzed. We observe qualitative changes in the behavior of biopixels and the biosensor model on hexagonal lattice using lattice difference equations with delay in general. Figures 3 and 4 show the first stage of computer modeling of discrete dynamics of an intelligent Big Data system for investigation of the stability of CPS of medical and biological processes in the form of lattice images of antigens and antibodies in pixels of the studied system. Figure 3 (a) shows the result of numerical simulation of system (4) at $r=5$, which corresponds to a stable focus. For $r=17$ there is less pronounced (Fig. 3 (b)), and for $r=22$ more pronounced wavy changes in the lattice images of antigens and antibodies in the pixels of the system (4), as shown in Figures 3 (c).

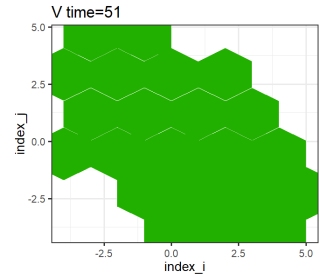

a)

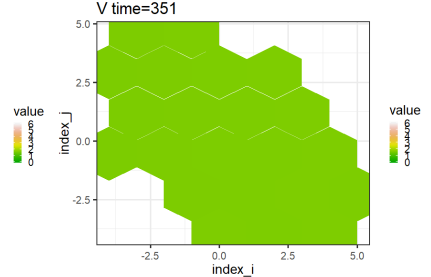

b)

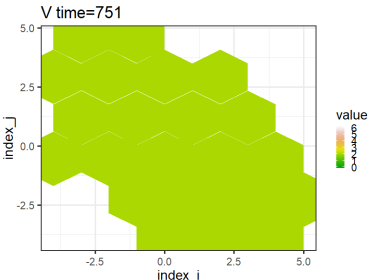

c)

Figure 3. Lattice images of antigens in pixels of system (4) at

$$
r=5(a), r=17(b), r=22(c)
$$

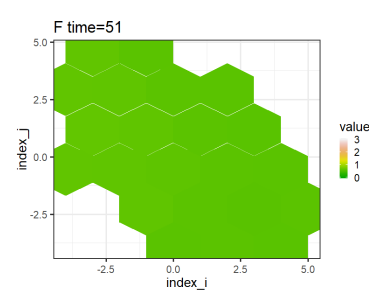

a)

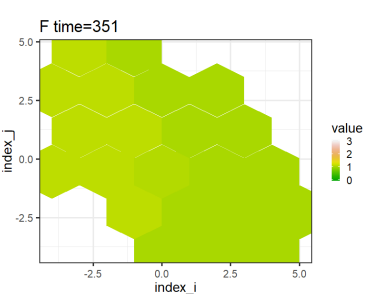

b)

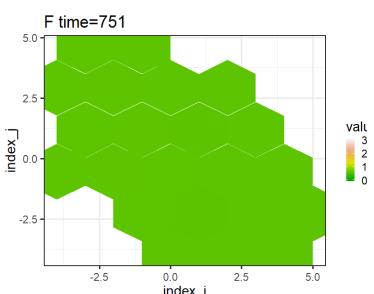

c)

Figure 4. Lattice images of antibodies in pixels of the system (4) at

$$
r=5(a), r=17(b), r=22(c)
$$

In the second stage of computer modeling of the intelligent Big Data system, lattice graphs were used to investigate the stability of the CPS of medical and biological processes. Firstly, the corresponding graphs are constructed, on which for each pixel the image of probability of contact of antigens with antibodies, as $V_{i, j, k} \times F_{i, j, k}$ at $r=5, r=17, r=22$ is presented in Figure $5(\mathrm{a}-\mathrm{c})$.

Figure 5 (a) shows the result of numerical simulation of system (4) at $r=5$, which corresponds to a stable focus. For $r=17$ there is less pronounced (Fig. 5 (b)), and 
for $r=22$ more pronounced wavy changes in the images of the probability of contact of antigens with antibodies of system (4), as shown in Figure 5 (c).

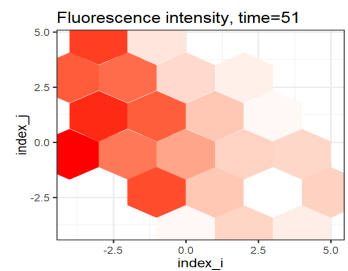

a)

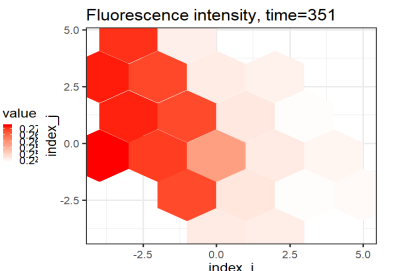

b)

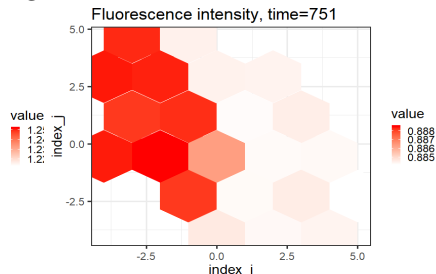

c)

Figure 5. Lattice images of antigen-antibody binding in pixels of system (4) at

$$
r=5(a), r=17(b), r=22(c)
$$

In the third stage of computer modeling of the intelligent Big Data system for investigation of the stability of CPS of medical and biological processes, lattice graphs of fluorescent pixels were obtained based on the fulfillment of condition (6).

The result of numerical simulation of system (4) at $r=5$, which corresponds to a stable focus. For $r=17$ there is a less pronounced and for $r=22$ - it is more pronounced traveling wave of fluorescent pixels of the system (4).

Hopf bifurcation is observed with increasing time delay [16]. The result of numerical simulation of the system (4) at $r=17$, which corresponds to the limit cycle (there is a traveling wave of fluorescent pixels). In the case $r=22$, chaotic behavior is observed, which begins with wave-like changes in fluorescent pixels and quickly turns into chaotic changes. A two-dimensional array of biopixels was used to develop the dynamic logic of an intelligent Big Data system to investigate the stability of the CPS of medical and biological processes on a hexagonal lattice using delay equations. As shown by the results of numerical analysis, fluorescent states in biopixels change according to the laws of discrete dynamics.

\section{Conclusion}

In the work the general scheme of the cyber-physical sensor system proposed in [17] was extended to the usage of Big Data. The basic model has been modified to take into account the features of biosensors. Lattice images in biopixels are modified according to the laws of discrete dynamics. The developed models take into account the interaction of biopixels with each other by antigen diffusion.

The mathematical description of the intelligent Big Data system for investigation the stability of CPS of medical and biological processes contains discrete population dynamics, which is combined with the dynamic logic used for discrete events. The paper uses a class of time-lattice difference equations that model the interaction of antigens and antibodies in biopixels. Spatial operators model the interaction of diffusion type between biopixels.

A set of computer programs for the study of the intelligent Big Data system for investigation the stability of CPS of medical and biological processes has been created, which can be used both separately and as additional specialized software, which makes it possible to study the of phase diagrams, lattice images of 
antigens/antibodies, lattice images of antigen binding to antibodies, images of fluorescent biopixels and electrical signal from the converter of the studied systems on a rectangular lattice using differential equations or hexagonal lattice using difference equations using the $\mathrm{R}$ package.

According to the results of a series of experiments of intelligent Big Data system for investigation of the stability of CPS of medical and biological processes using lattice difference equations with delay it is established that in case of using hexagonal lattice at For $r \in[0,16]$ the solution of the investigated system tend to non-identical endemic states, which are a stable focus. For $r=17$ (in the case of a hexagonal lattice) there is a Hopf bifurcation and all subsequent trajectories correspond to stable boundary cycles for all biopixels. With a further increase in the delay constant $r$, chaotic behavior of the CPS occurs on the basis of lattice difference equations.

The developed computer programs for the study stability of intelligent Big Data system for investigation the stability of CPS of medical and biological processes in the form of phase diagrams, lattice images of antigens/antibodies, lattice images of antigen binding to antibodies, images of fluorescent biopixels and the electrical signal from the converter should be used in research, design organizations, medical and laboratory centers in the development and testing of cyber-physical systems of medical and biological processes.

\section{REFERENCES}

1. RAY P. P., DASH D., KUMAR N.: Sensors for internet of medical things: Stateof-the-art, security and privacy issues, challenges and future directions, Computer Communications, Volume 160, 2020, 111-131

2. LLORET J., PARRA L., TAHA M., TOMÁS J.: An architecture and protocol for smart continuous eHealth monitoring using 5G, Computer Networks, Volume 129, Part 2, 2017, 340-351.

3. JAYATILLEKA M., HALGAMUGE N.: CHAPTER 1 - Internet of Things in healthcare: Smart devices, sensors, and systems related to diseases and health conditions, Editor(s): Himansu Das, Nilanjan Dey, Valentina Emilia Balas, In Advances in Ubiquitous Sensing Applications for Healthcare, Real-Time Data Analytics for Large Scale Sensor Data, Academic Press, Volume 6, 2020, 1-35.

4. YUAN B., SHEN C., LUNA A., KORKUT A., MARKS D. S., INGRAHAM J., SANDER CH.: CellBox: Interpretable Machine Learning for Perturbation Biology with Application to the Design of Cancer Combination Therapy, Cell Systems, Volume 12, Issue 2, 2021, 128-140.

5. SRIVATHSAN M., YOGESH ARJUN K.: Health Monitoring System by Prognotive Computing Using Big Data Analytics, Procedia Computer Science, Volume 50, 2015, 602-609.

6. KURIAN S. J., BHATTI A. R., ALVI M. A., TING H. H., STORLIE C., WILSON P. M., SHAH N. D., LIU H., BYDON M.: Correlations Between COVID-19 Cases and Google Trends Data in the United States: A State-by-State Analysis, Mayo Clinic Proceedings, Volume 95, Issue 11, 2020, 2370-2381.

7. KRAINYK Y., DAVYDENKO Y., STARCHENKO V.: Message-level Decoding of Error Patterns for Turbo-Product Codes, in: Proceedings of the 39th International Conference on Electronics and Nanotechnology (ELNANO), Kyiv, Ukraine, 2019, 660-663. 
8. REZAEI-RAVARI M., EFTEKHARI M., SABERI-MOVAHED F.: Regularizing extreme learning machine by dual locally linear embedding manifold learning for training multi-label neural network classifiers, Engineering Applications of Artificial Intelligence, Volume 97, 2021, 104062.

9. HUANG L., LENG H., LI X., REN K., SONG J., WANG D.: A Data-Driven Method for Hybrid Data Assimilation with Multilayer Perceptron, Big Data Research, Volume 23, 2021, 100179.

10. MARTSENYUK V.P., ANDRUSHCHAK I.YE.., ZINKO P.M., SVERSTIUK A.S.: On Application of Latticed Differential Equations with a Delay for Immunosensor Modeling. Journal of Automation and Information Sciences, Volume 50, Issue 6, 2018, 55-65.

11. MARTSENYUK V.P., SVERSTIUK A.S., ANDRUSHCHAK I.YE.: Approach to the Study of Global Asymptotic Stability of Lattice Differential Equations with Delay for Modeling of Immunosensors. Journal of Automation and Information Science, Volume 48, Issue 8, 2019, 58-71.

12. FORYS U.: Marchuk's model of immune system dynamics with application to tumour growth, Journal of Theoretical Medicine, Volume 4, no. 1, 2002, 85-93.

13. PRINDLE A., SAMAYOA P., RAZINKOV I., DANINO T., TSIMRING LS, HASTY J.: A sensing array of radically coupled genetic 'biopixels', Nature, Volume 481, no. 7379, Dec. 2011, 39-44.

14. PLATZER A.: The complete proof theory of hybrid systems. In 27th Annual ACM/IEEE Symposium on Logic in Computer Science, 2012, 541-550.

15. MARTSENYUK V.P., SVERSTIUK A.S., BAHRII-ZAIATS O.A., RUDYAK YU.A., SHELESTOVSKY B.: Software complex in the study of the mathematical model of cyber-physical systems. ICT\&ES 2nd International Workshop Information-Communication Technologies \& Embedded Systems, 12 November, 2020 Mykolaiv, Ukraine. Volume 1, 2020, 87-97.

16. DUAN D., NIU B., WEI J.: Hopf-Hopf bifurcation and chaotic attractors in a delayed diffusive predator-prey model with fear effect, Chaos, Solitons \& Fractals, Volume 123, 2019, 206-216.

17. BERGER C., HEES A., BRAUNREUTHER S., REINHART G.: Characterization of Cyber-Physical Sensor Systems. Procedia CIRP, Volume 41, 2016, 638-643. 